\title{
LA COOPERACIÓN INOLVIDABLE DE AIMÉ BONPLAND Y ALEXANDER VON HUMBOLDT
}

\author{
The unforgettable cooperation of Aimé Bonpland and Alexander von Humboldt
}

\author{
FRANK HOLL'잉
}

\begin{abstract}
Summary: The article analyses Aimé Bonpland's role during the American expedition with Alexander von Humboldt (1799 to 1804). This role was more important than previously assumed, as was Bonpland's later work in Latin America. Bonpland also conducted botanical, zoological and geological research there. Above all, he rendered outstanding services to agriculture there with new cultivation and breeding methods, especially in the cultivation of yerba mate. In his later years Bonpland initiated a project to transfer agriculturally useful plants from Argentina to the French colony of Algeria. Over 80 years old, from 1855 until his death in 1858, he worked as the first director on the establishment of a natural history museum in Corrientes. It was one of the oldest in Argentina and the first state institution in the interior of the country. Bonpland reflected on all this in a detailed correspondence with Alexander von Humboldt. The article also analyses the three contradictory reports by the German physician and travel writer Robert AvéLallemant, who visited Bonpland in Santa Ana shortly before his death. In doing so, he drew a negative image of the researcher that still influences historical record today. A correction is urgently needed.
\end{abstract}

Key words: Bonpland, cooperation, Corrientes, Humboldt, Museo Amado Bonpland, Santa Ana, yerba mate.

Resumen: El artículo analiza el papel de Aimé Bonpland durante su expedición americana con Alexander von Humboldt (1799 a 1804). Este papel fue mucho más importante de lo que se suponía, así como también el trabajo posterior de Bonpland en América Latina. Bonpland realizó allí valiosas investigaciones botánicas, zoológicas y geológicas. Sobre todo, prestó excelentes servicios a la agricultura de la zona con nuevos métodos de cultivo y cría, especialmente en el cultivo de la yerba mate. En sus últimos años Bonpland inició un proyecto para transferir plantas útiles para la agricultura de Argentina a la entonces colonia francesa de Argelia. De 1855 hasta su muerte (a los 85 años) en 1858, Bonpland trabajó como primer director para el museo de ciencias naturales en Corrientes. Es uno de los museos más antiguos de Argentina y el primero en ser institucionalizado en el interior del país. Bonpland describió todo esto en una detallada correspondencia con Alexander von Humboldt. El artículo también analiza los tres informes contradictorios del médico y escritor de viajes alemán Robert Avé-Lallemant, quien visitó a Bonpland en Santa Ana poco antes de su muerte. Al hacerlo, dibujó un cuadro negativo del investigador que aún hoy influye en la historiografía. Se necesita urgentemente una corrección.

Palabras clave: Bonpland, cooperación, Corrientes, Humboldt, Museo Amado Bonpland, Santa Ana, yerba mate.

${ }^{1}$ Autor científico independiente. Historiador, Universidad de Munich. Ex-Director de las "Jornadas de la Ciencia de Munich", Alemania. E-mail: frank.holl@gmail.com 


\section{La importancia de Bonpland}

;"Me voy a volver loco si las maravillas no terminan pronto"! 2 (Moheit, 1993: 42). Aimé Bonpland exclamó esta frase, una de las más significativas del viaje entero, cuando por primera vez contempló la inmensa variedad de los trópicos en el Mundo Nuevo. Su nombre estará para siempre unido a la gran expedición que le llevó junto a Alexander von Humboldt entre 1799 y 1804 a las colonias españolas de América. La contribución de Bonpland para que esta expedición fuese todo un éxito es gigantesca. Quiero expresar aquí mi deseo de llamarla la expedición Bonpland-Humboldt, ya que la queremos considerar en esta aportación desde la perspectiva de Aimé Bonpland.

En dos de los cuadros más célebres que fueron pintados en memoria del viaje se le puede contemplar junto a Alexander von Humboldt: una vez muy auténtico, precisamente en el de Friedrich Georg Weitsch de 1810, al herborizar con su estuche de herborización, con un cóndor cazado en primer plano y al fondo con un barómetro de viaje. Impresiona también el otro cuadro, el de Eduard Ender. Aquí sin embargo, se trata de una escenificación teatral que se creó más tarde, en 1856, cuando Bonpland ya tenía 83 y Humboldt 87 años. En este último cuadro además se pueden apreciar algunos instrumentos, aunque muchos de los que los investigadores no tenían consigo cuando se encontraban en el Orinoco, p. ej. un teodolito y un microscopio de cartón de Nuremberg (Kügelgen et Seeberger, 1999). A pesar de todo, el cuadro trasmite una impresión, aunque no muy auténtica, del trabajo de campo de los dos científicos.

Aimé Bonpland tiene su lugar fijo en la historia de los viajes científicos. Pero ¿cuál es su verdadera contribución en la gran expedición Bonpland-Humboldt?

\section{El éxito de viajes}

El éxito de un viaje de investigación se compone, según el biógrafo de Humboldt, Hanno Beck, de tres factores: la preparación, la realización y la elaboración o publicación

2 Alexander a Wilhelm von Humboldt, Cumaná, 16 de julio de 1799.
(Beck, 1985: 301). El viaje americano de Aimé Bonpland y Alexander von Humboldt fue conforme a esta perspectiva un éxito rotundo. Hasta hoy día un sinfín de historiadores que intentan dar una visión global se ocupan de dicho viaje, aunque también se ocupan del mismo investigadores de diferentes disciplinas científicas. Sin duda, la contribución de Bonpland fue especialmente importante en cuanto a la realización, en parte también en la elaboración del viaje. Sin embargo, la preparación corre por cuenta de Alexander von Humboldt. Echemos una breve mirada a la misma. Desde su juventud soñaba con una expedición a los trópicos. No le importaba si éstos fueran los asiáticos, los americanos o incluso los africanos. Con la muerte de su madre en el año 1796 y después de haber recibido una cuantiosa herencia estaba en condiciones de realizar dicho sueño como particular. "Tengo tanto dinero que me puedo dorar la nariz, la boca y las orejas"3 (Jahn et Lange, 1973: 136), escribió en 1791. Las cuestiones científicas y el objetivo del viaje ya los había elaborado durante sus estudios y durante su trabajo como responsable de las minas de Franconia. Había conseguido los instrumentos de medición en Alemania y aprendido cómo utilizarlos.

Al finalizar su trabajo como consejero superior de minas prusiano en diciembre de 1796, la finalidad de Humboldt fue primero emprender viaje en noviembre de 1797 con el inglés Lord Bristol a Egipto. Sin embargo, este plan no se realizó por la invasión de Napoleón en Italia y su posterior campaña a Egipto. Durante la estancia de Humboldt en París a partir de mayo de 1798 también se evaporó el sueño de una participación en la expedición estatal francesa de Nicolas Baudin. Ésta fue aplazada por razones financieras. Humboldt describe el plan original como sigue: " $E l$ primer año deberíamos pasar en Paraguay y en la Patagonia, el segundo en Perú, Chile, Méjico y California, el tercer año en el Mar del sur, el cuarto en Madagascar y el quinto en Guinea"4 (Päßler et al., 2019).

\footnotetext{
${ }^{3}$ Humboldt a Paul Christian Wattenbach, Escheburg, antes del 26 de abril de 1791.

${ }^{4}$ Alexandervon Humboldta Karl Ludwig Willdenow. Aranjuez, 20 de abril de 1799. https://edition-humboldt.de/v5/H0001200
} 
Durante la planificación de esta vuelta al mundo conoció a Aimé Bonpland en París. Éste igualmente había sido elegido como miembro de la expedición de Baudin. Humboldt le invitó de acompañarle con los costos pagados en su viaje de exploración. Primero quería pasar con Bonpland desde Marsella a Argel o Trípoli en un barco del cónsul general de Suecia de Argel, Matthias Archimboldus Skjöldebrand que Humboldt había conocido en París. Desde allí, Humboldt tenía la intención de juntarse en Egipto con el ejército napoleónico y los científicos franceses que le acompañaban. Sobre Bonpland escribió en aquella época a su amigo y colega, el botánico berlinés, Karl Willdenow, lo siguiente: "Me junté con uno de los participantes que fueron elegidos para el viaje alrededor del mundo, Bonpland, un botanista muy bueno, el mejor alumno de Jussieu y Desfontaines" ". Ha servido en la marina, está fuerte, tiene coraje y buen corazón y es hábil en la "anatomia comparata"'6 (Päßler et al., 2019).

Casi durante dos meses, desde octubre hasta la mitad de diciembre de 1798, Bonpland y Humboldt esperaron en Marsella para poder cruzar al Norte de África. Sin embargo, por la enemistad entre Argelia y Túnez contra Francia, también se estropeó dicho plan. Humboldt escribió en su diario: "Si hubiese estado solo, si Bonpland hubiese mostrado entusiasmo en vez de resistencia, yo hubiese cumplido mi objetivo. El plan era atrevido, sin duda, pero ¿no se queda uno fácilmente en inactividad si uno no se atreve a nada? Bueno, entonces ahora rumbo a España, quizás nos quedaremos entre 6 y 8 meses en suelo europeo" (Faak, 2000: 55).

Fue entonces la nacionalidad francesa de Bonpland el impedimento para que los dos tuvieran que renunciar al viaje a África y Egipto y hacer sus investigaciones allí. Por dicha circunstancia Bonpland tuvo, sin mayor intencionalidad, la máxima influencia en la realización de la expedición americana. Este viaje fue el siguiente plan de Humboldt.

\footnotetext{
${ }^{5}$ Antoine-Laurent Jussieu y René-Louiche Desfontaines eran profesores con mucho renombre en el Muséum d'Histoire Naturelle y miembros de la Academia de Ciencias de París.

${ }^{6}$ Alexander von Humboldta Karl Ludwig Willdenow. Aranjuez, 20 de abril de 1799. https://edition-humboldt.de/v5/H0001181
}

Únicamente fue posible porque hizo sus gestiones muy hábilmente en la corte española y consiguió un pasaporte que le aseguró la libertad para llevar a cabo sus investigaciones en las colonias españolas. En el pasaporte figuró Bonpland como "Ayudante o Secretario"" (Holl, 2001: 30) y fue finalmente la posibilidad más simple para ambos investigadores para poder viajar juntos. Como científico independiente francés, Bonpland hubiese despertado en las colonias españolas mucha más desconfianza que el hombre privado prusiano Humboldt, ya que Prusia no tenía en aquella época intereses coloniales. Posteriormente se complementaron los dos no únicamente en el ámbito científico, sino también como excelentes compañeros de viaje. Durante toda la expedición como también más tarde, durante toda la vida, su relación estaba marcada por un gran respeto mutuo. Durante su viaje, el 21 de febrero de 1802, Humboldt escribió a su amigo Willdenow en Berlín:

"Con mi compañero de viaje Alexandre [sic] Bonpland estoy muy contento. Es un alumno digno de Jussieu, Desfontaines y especialmente del viejo raro [Louis Claude] Richard (que debe ser el mejor botanista de Paris). Es sumamente activo, trabaja mucho, se adapta fácilmente a costumbres y personas, habla muy bien español, tiene mucho coraje y no tiene miedo a nada. Demuestra unas condiciones excelentes para un viajero naturalista"8 (Päßler et al., 2019).

Bonpland fue el único que acompañó a Humboldt desde el principio hasta el final del viaje. Humboldt se ha manifestado durante el viaje en todas sus cartas y también en su diario de viaje, y posteriormente solo de manera positiva sobre el mismo. Ambos investigadores se han protegido también en situaciones amenazantes de manera muy ejemplar. Cuando su barco estaba a punto de volcar en el Orinoco, Bonpland le ofreció a Humboldt que no sabía nadar, salvarlo. Y cuando Bonpland después de la expedición al Orinoco estuvo gravemente enfermo, Humboldt se ocupó de él. También durante otra enfermedad en Bogotá Humboldt esperó pacientemente hasta que se mejorara.

\footnotetext{
${ }^{7}$ Transcripción del pasaporte de Humboldt.

${ }^{8}$ Alexander von Humboldt a Karl Ludwig Willdenow. Havanna, 21 de febrero de 1801.
} 
Al final del viaje, en junio de 1804, Bonpland escribió desde Washington a Alire RaffeneauDelile:

"Nosotros vivimos juntos (Humboldt y yo) como dos amigos, como dos hermanos: lo que es suyo es mio, lo que es mío le pertenece a él. La gran armonía que hemos vivido durante este largo tiempo nos ha hecho olvidar las penurias innombrables que hemos vivido entre los salvajes del Orinoco, del Río Negro, del Amazonas y en las cumbres heladas de las grandes cordilleras de los Andes" (Hamy, 1906: 8).

Durante el viaje Bonpland era el hombre que se ocupaba de los detalles botánicos y zoológicos. Humboldt, por el contrario, era el que los situaba de manera holística. Esto se demuestra en su programa científico que elaboró poco tiempo antes de su partida de España en Madrid:

"Coleccionaré plantas y animales, estudiaré la temperatura, la elasticidad, la composición magnética y eléctrica de la atmósfera, la descompondré, determinaré las longitudes y los paralelos geográficos, mediré montañas; pero, en realidad, éste no es mi objetivo final. Mi verdadera y única finalidad será la de investigar cómo se entretejen todas las fuerzas naturales, la influencia de la naturaleza muerta sobre el mundo vivo animal y vegetal' 10 (Jahn et Lang, 1973: 657).

Con dicho objetivo científico definió, sin conocer el término, la ecología moderna. Es significativo en su programa que la botánica figura en primer lugar. No solamente en las publicaciones posteriores, la gran obra del viaje la cual mencionaré más tarde, la botánica tiene un papel central.

\section{La relevancia de la botánica}

En su introducción a la descripción general del Viaje a las regiones equinocciales del nuevo continente, dice Humboldt:

"Amaba apasionadamente la botánica y algunos ámbitos de la zoología. [...] Sin

\footnotetext{
${ }^{9}$ Bonpland a Alire Raffeneau-Delile, Washington, junio de 1804.

${ }^{10}$ Humboldt a Moses Friedländer, Madrid, 11 de abril de 1799. Allí se denomina carta a David Friedländer.
}

embargo, dado que habia preferido siempre observar la relación entre hechos que se habian observado desde hace mucho tiempo antes de tomar conocimiento de hechos aislados aunque sean nuevos, me parecia mucho menos importante el descubrimiento de un género desconocido que la investigación de condiciones geográficas del mundo de las plantas y observaciones sobre el movimiento de las plantas sociables y sobre la altitud en la cual se instalan las diferentes especies mirando hacia la cima de las cordilleras" (Humboldt, 1991: 12-13).

Durante el viaje de investigación de cinco años (1799 hasta 1804) la botánica estuvo en el centro de las exploraciones de los dos investigadores, más que cualquier otra cosa. Mientras que duraba dicho viaje americano, que les llevó por regiones que hoy día se llaman Venezuela, Cuba, Colombia, Ecuador, Perú y Méjico, Alexander von Humboldt, y especialmente Aimé Bonpland, han descrito por primera vez cientos de plantas desconocidas hasta entonces para la ciencia internacional, las han reflejado por primera vez en su libro de viaje y les han dado nombres vinculantes (Lack, 2009: 7). Ambos investigadores han llevado un diario de viaje. El de Humboldt, por su perspectiva más global, es más detallado en cuanto a su temática, aunque también contiene múltiples referencias a la botánica. Bonpland escribió su así llamado "Journal Botanique". Tal como el de Humboldt, no es un diario propiamente dicho, el "Journal" de Bonpland es un libro de campo. Contiene la descripción de muchas plantas y animales que observó y coleccionó en el campo así como determinaciones previas. En la mayor parte es numerado cronológicamente (1 a 4.528 para plantas, 1 a 33 para animales) (Lack, 2009: 23). En la encuadernación original abarca siete cuadernos. Fue la base de la publicación científica posterior del resultado botánico del viaje y se conserva en la "Bibliothèque Centrale del Muséum National d'Histoire Naturelle" en París (Lack, 2009: 23). Se encuentran en él aparte de las descripciones de las plantas de Bonpland también algunas observaciones complementarias de la mano de Humboldt. Más tarde, el 21 de julio de 1851, casi 47 años después del regreso de la expedición, Humboldt se acuerda: "Aunque haya partes entre estos documentos que hayan 
sido redactados por mí, debo considerar el conjunto como propiedad del Sr. Bonpland" (Lack, 2009: 26). Se encuentran en muchas partes asignaciones al sistema de Linné y muestran que éstas se utilizaban como método de clasificación práctica en el campo. Las descripciones se realizaban en latín y en francés y se adjuntaban a menudo pequeños bosquejos. Lamentablemente no se encuentran ni en éste ni en otro diario relatos personales del viaje de Bonpland.

Más importante que el "Journal Botanique" son las plantas o partes de plantas que se habían coleccionado, prensado y secado entre hojas de papel durante la expedición. Es difícil opinar sobre la cantidad conservada y perdida de las mismas. Existe una carta de Humboldt del 21 de febrero de 1801 desde La Habana que nos da una idea del trabajo de ambos investigadores:

"Sería muy triste de obtener la información de que los frutos [...] del trabajo [de Bonpland] se hubiesen perdido. Para evitar esto hemos hecho copias de nuestras descripciones (2 volúmenes que contienen hoy 1400 especies, solamente raras y nuevas). Nosotros conservamos un manuscrito con nosotros, la copia enviamos parcialmente a través de los Vice-Cónsules franceses a Francia, al hermano de Bonpland a La Rochelle. Hemos repartido las plantas en 3 colecciones, ya que tenemos dobles y triples de todo. Cargamos y llevamos con nosotros alrededor del mundo un herbario de menores dimensiones, para comparar. Un segundo herbario (que pertenece a Bonpland con el cual comparto todo por supuesto) se ha enviado ya a Francia y el tercero (en 2 cajas con criptogámicos y hierbas que contienen 1.600 diferentes especies, mayormente de la parte desconocida de Parime y Guayana entre el Río Negro y Brasil donde estuvimos en la primavera pasada) será enviado hoy a través del Sr. John Fraser vía Charleston hacia Londres. [...] Él solo ha secado las plantas con sus dobles, más que 12.000, las descripciones son más o menos su obra en cuanto a la mitad. A menudo hemos descrito cada uno por su cuenta la misma planta para estar más seguros"11 (Päßler et al., 2019).

Durante su viaje los investigadores enviaron a menudo los objetos coleccionados,

\footnotetext{
${ }^{11}$ Alexander von Humboldt a Karl Ludwig Willdenow. Havanna, 21 de febrero de 1801. https://edition-humboldt.de/v5/H0001181
}

no solo los botánicos, con informaciones científicas por vías diferentes a Europa. En su mayoría se coleccionaron dobles y triples. Las plantas secadas que llegaron sin daños a Europa, por envíos o más tarde por los investigadores mismos, se encuentran hoy día mayormente en dos museos: en el "Muséum National d"Histoire Naturelle" en París y en el "Botanisches Museum de Berlín-Dahlem".

El secado de las plantas y el dibujo no fueron, sin embargo, la única posibilidad de enviar material vívido para su elaboración y como modelo para dibujantes y grabadores de cobre a Europa. Una alternativa era la autoimpresión natural. Para dicho procedimiento imprimieron Bonpland y Humboldt plantas prensadas pero no necesariamente secas con tinta de impresión, utilizaron éstas como modelo de impresión y las imprimieron en papel. Este método, aunque diese imágenes bastante bastas, tenía la ventaja que dichos resultados sobre el papel fuesen atacados mucho menos por insectos. Posiblemente serían estos dos investigadores los únicos que utilizaban este procedimiento. No se ha comprobado en ninguna de las expediciones posteriores (Lack, 2009: 30). También enviaron o trajeron semillas de plantas a Europa. A posteriori se intentó cultivarlas con mayor o menor éxito en los jardines botánicos de París, Madrid, Copenhague y Berlín (Lack, 2009: 30). Sin embargo, no se puede especificar la magnitud y la cantidad de los ejemplares de los herbarios en su totalidad, lamenta Hans Walter Lack, uno de los más importantes conocedores de las investigaciones botánicas de esta expedición (Lack, 2009: 34).

Solo después del regreso del viaje americano empezaron los dos investigadores con la evaluación de las colecciones para su publicación. Sin embargo, durante su viaje Humboldt ya expuso un resultado importante de sus investigaciones botánicas: Era la geografía de las plantas. En enero y febrero de 1803 ya hizo un bosquejo en acuarela en el puerto de Guayaquil. Introdujo en un perfil de la región de los Andes en el Ecuador los nombres de las plantas observadas de la región del Chimborazo en relación a su altura. Fue una realización que hizo mucho antes 
del análisis y de la descripción de las plantas coleccionadas con Bonpland.

Fue en el año 1807 que se realizó la verdadera publicación del grabado colorado de la "Géographie des plantes dans les Régions equinoxiales, Tableau phisique des Andes", junto con un volumen explícito. Como autores se citan Alexander von Humboldt y Aimé Bonpland aunque el verdadero autor fue Alexander von Humboldt. Con dicha obra creó una nueva disciplina científica, la geografía de las plantas. En un gran cuadro de la naturaleza ("Naturgemälde") Humboldt relacionó las observaciones de ambos investigadores que se hicieron en la región del ecuador con la altura. Este trabajo demuestra también su pensamiento ecológico, su interés de investigar "cómo se entretejen todas las fuerzas naturales"12 (Jahn et Lange, 1973: 657), tal como lo había expresado en 1799 en Madrid. En una visión global unía observaciones botánicas, zoológicas, meteorológicas, climatológicas, pero también observaciones en la agricultura con mediciones físicas. La obra formó parte de la implementación consecuente de su objetivo científico creado durante su juventud mientras estudiaba y durante su tiempo en Franconia como responsable de las minas prusianas.

Ya en junio de 1795, Goethe le había escrito: "Dado que sus observaciones parten del elemento y los míos de la forma, no debemos tardar en encontrarnos en el medio"13 (Jahn et Lange, 1973: 435). Alexander von Humboldt en aquel entonces, todavía había insistido mucho en los elementos singulares, que pretendía coleccionar e investigar con la ayuda de instrumentos de medición, configuraciones experimentales y cálculos. Su encuentro con Goethe, sin embargo, fue el inicio de su toma en consideración cada vez más pronunciada de la totalidad, la forma de la naturaleza, su totalidad. Lentamente y a partir de entonces, empezó a comprender los aspectos particulares de la naturaleza como la totalidad dinámica organizada, es decir como la totalidad animada

12 Humboldt a Moses Friedländer, Madrid, 11 de abril de 1799.

${ }^{13}$ Johann Wolfgang von Goethe a Humboldt, sin lugar, 18 de junio de 1795. y sus interrelaciones. Desde entonces el objetivo de Humboldt fue, tal como lo expresó más tarde en el "Kosmos", "comprender el espíritu de la naturaleza, que se encuentra escondido bajo el manto de las apariciones. De esta manera podemos lograr de entender la naturaleza y de dominar a través de ideas la materia bruta de las percepciones empiricas" (Humboldt, 1845: 6).

Con su "Géographie des Plantes dans les Régions Equinoxiales" Humboldt unió de manera excepcional el proceder empírico con la síntesis. Es la demostración de su camino desde lo particular a lo global. El hecho de que dicha transposición gráfica ya se hizo durante su viaje y que publicara esta idea después del viaje como primer paso, sin haber evaluado las plantas en detalle, por un lado es lógico, pero también evoca sorpresa. Hans Walter Lack escribe: "Mientras que por reglas generales se describen los modelos de la distribución de las plantas (y de los animales) en el espacio después de haber descrito y determinado los organismos encontrados, se observa un procedimiento totalmente inverso en el Essai [sobre la geografía de las plantas]". Fue, según Lack, "un logro genial y al mismo tiempo atrevido, de llevar a cabo la síntesis antes del análisis y también de publicar los resultados integrantes y generalmente válidos en anticipación a la parte específica" (Lack, 2003).

La geografía de las plantas apareció en 1807 como "Partie 5" de la obra total del viaje. Fue publicada entonces dos décadas antes de la terminación de la parte específica botánica principal, de la "Partie 6". Constituye el testimonio del pensamiento ecológico de Humboldt, un concepto que no se conocía todavía. Tampoco se conocía el concepto de la biodiversidad que se consagró en 1985 (Lack, 2009: 9). Y sin embargo implanta la geografía de las plantas justamente en un gran cuadro: la diversidad de la vida en el mundo de los trópicos.

\section{Evaluación y publicación del viaje americano}

Al final de casi seis años, Bonpland y Humboldt regresaron el 27 de agosto de 1804 a París. Comenzaron en seguida con la evaluación 
del material y la preparación de la publicación de los resultados. Es el gran logro de ambos científicos que los resultados botánicos de su viaje fuesen realmente publicados en el curso de los próximos años. Además se debe destacar que Bonpland y Humboldt no eran los únicos que habían investigado en las colonias españolas. El rey español Carlos III había enviado no menos que siete expediciones también con orientación botánica a sus dominios americanos. Sin embargo, la gran masa de lo investigado quedó por múltiples razones durante mucho tiempo sin publicar (Lack, 2009: 9). La "Partie 6 Botanique" del "Voyage aux régions équinoxiales du nouveau continent" fue una gran excepción y contribuyó en especial medida a la gran fama del viaje de investigación hasta hoy día.

La botánica, con mucha distancia, forma la mayor parte de los 29 tomos de la obra del viaje. Abarca en total 19 tomos ${ }^{14}$. Impresiona también la parte de la botánica en cuanto a los grabados de cobre: De la totalidad de 1.334 tablas 1.274 se dedican a la flora, es decir el 95,5\% (Glaubrecht, 2019).

La obra total lleva el título "Voyage aux régions équinoxiales du nouveau continent" y el nombre de los dos autores Alexander von Humboldt y Aimé Bonpland. Que figuren estos dos nombres como autores fue de gran importancia para Alexander von Humboldt. Aimé Bonpland fue por consiguiente también nombrado como autor en tomos en los cuales no había colaborado directamente, como p. ej. en los tomos de la astronomía, en los cinco atlas o en los dos Ensayos políticos sobre la Nueva España y Cuba. Sin embargo, ha logrado sus méritos también durante el viaje para la investigación zoológica y la publicación de los dos tomos correspondientes. Sin embargo, participó en medida muy decisiva en la "Partie 6 Botanique" del "Voyage aux régions équinoxiales du nouveau continent".

Lo que ambos investigadores sin embargo no preveían, era que la publicación tendría

\footnotetext{
${ }^{14}$ Según Lack, p. 11 la manera de contabilizar los tomos en su totalidad y en cuanto a la botánica es variable. Esto corresponde a la complicación en cuanto a la aparición. Cf. Horst Fiedler y Ulrike Leitner: Alexander von Humboldts Schriften. Bibliographie der selbständig erschienenen Werke. Berlin: Akademie-Verlag, 2000, p. 69 y 250.
}

una duración de casi tres décadas. Con el "Muséum National d"Histoire Naturelle" acordó Humboldt, que éste debería recibir una parte esencial del herbario coleccionado durante el viaje con aproximadamente 6.000 especies. Calculó que en ello se encontrarían aproximadamente entre 1.500 y 2.000 especies desconocidos. Como contrapartida, Bonpland debería ser reconocido "como viajero cientifico y recibir una pensión que le podría proporcionar un cierto sustento para poder publicar en los años posteriores sus trabajos "15 (Lack, 2009: 52). Además, Bonpland se empleó como responsable de los jardines de la esposa de Napoleón, la Emperatriz Joséphine, en el parque de La Malmaison. Sin embargo, fue lento en la elaboración muy meticulosa de las colecciones del viaje. Sólo trabajó en los primeros tomos de las "Plantes équinoxiales". En contra de las expectativas de Humboldt la publicación tardó desde mayo de 1805 hasta junio de 1817. Es decir, en los más de 12 años solo aparecieron 17 entregas con 140 tablas y solo se habían descrito algo más de 140 diferentes plantas (Lack, 2009: 58).

Dos de las siguientes razones fueron indicios para dicho retraso en cuanto a la publicación: la bancarrota de varios editores de la obra y el trabajo lento de Bonpland. En La Malmaison Bonpland estuvo a partir de 1810 tan ocupado que su participación en la parte botánica de la obra del viaje americano se atascó. Humboldt se vio en la obligación de enviarle varias cartas para llamarle la atención:

"Te ruego de nuevo, querido Bonpland, de ocuparte de terminar un objeto que es de tan alta importancia para las ciencias, para tu reputación moral y para los compromisos que contrajiste conmigo en 1798. Te ruego trasmitirnos el manuscrito, porque tú sabes que las afirmaciones de que tienes ya todo hecho no contribuyen en nada a adelantar este asunto. Me veo obligado a hacerte de nuevo estas súplicas porque acabo de pagar a $M$. Willdenow 3.000 francos de adelanto por las especies, y porque el público, que piensa que tú ya no te ocupas de las ciencias desde hace dos

\footnotetext{
15 Humboldt a Jean-Baptiste-Nampère de Champagny, entre el 2 de diciembre de 1804 y el 10 de marzo de 1805.
} 
años, no querrá una nueva obra de botánica sin que esté acabada la primera. [...] Espero que muy pronto te veamos aquí, mi querido Bonpland; te abrazo de todo corazón y sabré dentro de un mes si todavía me quieres algo, haciendo lo que yo te pido"16 (Minguet, 1989: 153).

Finalmente Humboldt tuvo que reconocer que Bonpland no podía entregar la evaluación científica de las plantas que se esperaba de él en el tiempo estipulado. El 17 de mayo de 1810 se dirigió desde París a Willdenow en Berlín y le solicitó su ayuda:

"El objetivo de estas líneas es una petición [...] La botánica se queda [en la publicación] muy atrasada. [...] Bonpland se ha volcado en la administración [de Malmaison], tiene un sueldo de 12.000 Livres y promete trabajos cientificos que no puede entregar, aún con buena voluntad no podría entregarlos. Sería inútil de quejarse del tiempo perdido. Hay que buscar mejores medidas para el futuro. Bonpland tiene las mejores disposiciones en cuanto a su corazón le dicta. Tengo excelentes relaciones amistosas con él, sin embargo, ni yo ni él mismo tienen influencia en él" ${ }^{17}$ (Päßler et al., 2019).

No obstante, serían solamente pocos meses que se quedara Willdenow en París. Volvió a Berlín, enfermó y se murió poco después. En el año 1813 el alumno de él, Carl Sigismund Kunth, un sobrino del antiguo profesor privado de los hermanos Humboldt y administrador del Castillo de Tegel, tomó las riendas de la elaboración científica de los tesoros botánicos. Hasta el año 1825 publicó en siete tomos con 700 tablas coloradas de cobre más de 4.500 plantas, entre ellos 3.600 hasta entonces desconocidas. Con este ritmo gigantesco de trabajo, Kunth se convirtió en el salvador de las publicaciones botánicas de Humboldt y Bonpland. Con la publicación de la última entrega de la "Revision des Graminées" finalmente concluyó la obra botánica en el año 1834 (Lack, 2009: 63; Schneppen, 2002: 10). Sin embargo, Humboldt, con la publicación de la obra total del viaje había extenuado

\footnotetext{
${ }^{16}$ Humboldt a Bonpland, París, 7 de septiembre 1810.

${ }^{17}$ Humboldt a Karl Ludwig Willdenow. Paris, 17 de mayo de 1810. https://edition-humboldt.de/v5/H0006055
}

completamente sus recursos económicos. En el año 1822 resultó estar "pobre como un ratón de iglesia", tal como escribió desde París $^{18}$ (Humboldt, 1880: 112). Cinco años después no vio otra posibilidad que abandonar París, ciudad tan querida al lado del Sena, y ponerse a disposición del Rey de Prusia como chambelán.

Ocho años antes, también Bonpland se vio enfrentado a problemas existenciales similares. El 29 de mayo de 1814 se murió su empleadora, la emperatriz Joséphine. Poco antes los aliados habían enviado a Napoleón al exilio de la isla de Elba. Fue urgente que se ubicase en una nueva ocupación y nuevos objetivos. Se acercó al círculo de Simón Bolívar, el posterior Libertador, que se había propuesto de luchar por la independencia de las colonias españolas en América Latina. Bonpland abandonó París en el otoño de 1816. Quería viajar desde Le Havre a Buenos Aires para establecerse allí. Se llevó una parte importante del material herborizado y coleccionado con Humboldt. Entre dicho material se encontraban también muchas plantas ya evaluadas y publicadas. Con ello se redujo la masa sobre la cual basaba Kunth su trabajo. Lo peor fue que Bonpland también se llevó el imprescindible "Journal botanique" con las descripciones detalladas de campo, clasificaciones preliminares e indicaciones de su lugar de origen. Humboldt envió a Kunth a Le Havre. Allí imploró a Bonpland de entregar el material herborizado. Sin éxito. En una carta dirigida a Humboldt, Bonpland quiso justificar esta postura el 19 de noviembre de 1816 desde Le Havre con el hecho de que el barco ya había pasado los trámites de la Aduana. Solo se estaban esperando los vientos favorables. Las cajas con el material herborizado, escribió Bonpland, se encontraban al fondo del barco. No era posible recuperarlas sin que se descargara todo el barco $^{19}$ (Hamy, 1906: 75-78).

Felizmente Bonpland fue tan generoso de entregar a Kunth el "Journal botanique" en "Le Havre". Sin él, Kunth no hubiese podido

\footnotetext{
${ }^{18}$ Alexander a Wilhelm von Humboldt, Florencia, 17 de diciembre de 1822.

19 Bonpland a Humboldt, Le Havre de Grâce, le 19 novembre 1816.
} 
continuar su trabajo y Humboldt hubiese estado obligado a abandonar la publicación de la "Partie 6". Las hojas de la herborización, sin embargo, se quedaron en Argentina en contra de lo que Bonpland había prometido a Humboldt. Poco tiempo después de la llegada de Bonpland a Argentina el país había conseguido su independencia. El 28 de enero de 1818, Humboldt, en una nueva carta, le implora nuevamente a su compañero de viaje de enviarle de vuelta a París el material que se había llevado al Cono Sur:

"Te conjuro, mi querido Bonpland, de enviarnos las plantas que has prometido para los Nova Genera y que han sido colocadas en tus cajas, hasta contra de tu voluntad; sabes bien qué falta nos hacen, esperemos que las enviaras apenas llegues a Buenos Aires. Tú puedes enviar esas cartas bien sea a Londres, a mi hermano ministro de Prusia, bien a $M$. Park o a mí en París, bien al Presidente del Instituto.

Pongo mucho empeño en esta súplica. Adiós, mi querido y viejo amigo, presenta las afectuosas expresiones de mi recuerdo $y$ mis respetos a madame Bonpland, Kunth me encarga transmitirte mil saludos. Te renuevo mi tierna amistad""20 (Minguet, 1989: 163).

Sin embargo, la petición de Humboldt cayó en saco roto. Grandes partes de los ejemplares herborizados que se llevó Bonpland a Argentina volvieron apenas en el año 1833 al museo de París (Lack, 2009: 74).

\section{Bonpland en Latinoamérica}

Ya antes de su viaje a Sudamérica Simón Bolívar había expresado su deseo que Aimé Bonpland fuese el sucesor de José Celestino Mutis. Bonpland había conocido en 1801 al botánico más famoso de Latinoamérica durante su gran viaje junto a Humboldt en Bogotá. Mutis había fallecido en 1808. Hubiese sido un cargo muy honorable. Sin embargo, los dos patriotas argentinos Manuel Belgrano y Bernardino Rivadavia convencieron a Bonpland en Londres de cambiar sus planes. Viajó a Argentina no solo con su colección de ejemplares herborizados, si no con una gran

${ }^{20}$ Humboldt a Bonpland, París, 28 de enero 1818. cantidad de semillas y plantas de semilleros para promover la agricultura. Junto a él se encontraba su esposa Adeline y la hija de ésta. Según el deseo del gobierno, Bonpland primero se hizo cargo de la cátedra para ciencias naturales en Buenos Aires. Sin embargo y dado que la Universidad no pagaba tal actividad (Bell, 2010: 34), le pareció mucho más sensato de aplicar sus conocimientos científicos a la práctica, es decir, de introducir nuevos métodos de cultivo y de introducirles en la práctica de la agricultura, y de trabajar como médico. En el año 1820 viajó a la región del Río Uruguay y del Paraná, a la provincia de Misiones. Quería transformar la vieja reducción jesuítica Santa Ana en una segunda Malmaison (Bell, 2010: 221) y comenzó allí mismo el cultivo de la yerba mate. Había descubierto, en contra de los conocimientos de aquella época, que la yerba mate (Ilex paraguayensis) no solo se podía recolectar en la selva salvaje sino también en plantaciones comercialmente mucho más eficientes $^{21}$ (Hossard, 2004: 93). Con ello entró en conflicto con la vecina Paraguay, que pretendía producir el mejor mate. La exportación de mate era la mayor fuente de ingresos del estado. El dictador de Paraguay, José Gaspar Rodríguez de Francia, vio invadido sus intereses a través de las actividades de Bonpland fuera de sus fronteras. También creía que el asentamiento de Bonpland fue creado para facilitar desde allí la invasión a Paraguay desde el lado argentino. De tal manera, el 8 de diciembre de 1821 aproximadamente 600 soldados aparecieron en Santa Ana. Asesinaron a 19 empleados de Bonpland, destruyeron sus plantaciones, le hirieron con golpes de sable, le secuestraron junto a otros 63 detenidos y le llevaron al territorio paraguayo (Bell, 2010: 62).

Bonpland desde entonces pasó casi diez años de su vida en Santa María en Paraguay. Nunca vio al dictador. Aunque estaba libre en cuanto a sus actividades, no estaba autorizado a abandonar su lugar de confinamiento. También estaba prohibido comunicarse con el mundo exterior. No existe ninguna carta de él de dicho tiempo y parece que no le llegó ningún escrito en dichos años. A causa del confinamiento

${ }^{21}$ Bonpland a Humboldt, Buenos Aires, August 1832. 
solo pudo leer diez años más tarde una carta de Humboldt que éste le dirigió el 25 de noviembre de 1821 desde París. Cuando le escribió, Bonpland no era todavía prisionero del dictador. Sin embargo, Humboldt estaba preocupado por las noticias que le llegaron al regreso del enviado prusiano a Brasil:

"Mi querido y excelente amigo, nunca uno se queja de aquellos a los cuales uno está unido por todos los lazos de la cálida amistad. Tu silencio prolongado me ha causado a menudo dolor. Sin embargo, no quiero creer que te hayas olvidado de tu antiguo compañero con el cual has compartido toda clase de suerte. Un amigo que nunca se olvidará lo que tú has hecho para él en las situaciones más dificiles de la vida"22 (Schneppen, 2002: 13).

Decía en su carta que había oído que Bonpland tenía problemas financieros: "Aprovecho esta oportunidad de enviarte la suma ridícula de 500 Piaster. [...] Te enviaría el doble si yo no estuviera pobre, igual que tú". La carta termina con "miles de saludos afectuosos". En el margen agrega Humboldt: "Te suplico que aceptes este dinero" (Schneppen, 2002: 13).

Cuando Humboldt se enteró más tarde del confinamiento de Bonpland, le pidió a Simón Bolívar con el cual mantenía contactos amistosos, que le ayudara. Éste se dirigió desde Lima en un escrito al dictador de Paraguay y le pidió la libertad de Bonpland. Bolívar incluso contempló una intervención militar e implicó a su compañero de lucha Antonio José de Sucre, el presidente de Bolivia. Sin embargo, todo fue inútil. También la esposa de Bonpland, Adeline, que se había instalado con él y la hija de su primer matrimonio en Latinoamérica, imploró la libertad para su marido. En un artículo de prensa del año 1834 se lee que Adeline viajaba constantemente entre Europa y América durante seis años para conseguir la libertad de su marido. Durante esta misión visitó Rio de Janeiro, París, Jamaica, Lima y Nueva York (Bell, 2010: 253-254 nota al pie 42). Sin embargo, sus pasos en los años posteriores se han perdido.

Cuando Humboldt en 1823 se enteró que el naturalista francés, Richard Grandsire,

22 Humboldt a Bonpland, Paris, 25 de noviembre de 1821. planificaba un viaje a Paraguay, inició un escrito con diferentes miembros de la Academia francesa de las Ciencias. En dicho escrito se exigió a Francia en el nombre de la ciencia liberar a Bonpland. Aunque también esta misión fracasó, dado que Francia no dejó entrar a Grandsire a Paraguay para tener nuevas deliberaciones con él (Schneppen, 2002: 1820). Humboldt intervino igualmente a través del Ministro de Exteriores inglés Canning. Hasta habló a Goethe del destino de Bonpland. Todo en vano (Schneppen, 2002: 20-21).

Tan sorprendente fue la súbita captura, tal fue la puesta en libertad de Bonpland. Sin previo aviso obtuvo el 12 de mayo de 1829 la orden de prepararse para un viaje, aunque tuvo que esperar todavía 20 meses en Itapúa, cerca de la frontera con Brasil hasta que pudo cruzar el Paraná. Su primera nueva estancia fue San Borja al lado del Río Uruguay en Brasil. En cartas que escribió desde allí a sus amigos, Bonpland también dibujaba las partes positivas que había tenido su confinamiento en Paraguay. Aunque había estado exento por completo de la comunicación ante todo con su familia y sus colegas científicos, dijo que se había ganado la vida con sus servicios médicos y su agricultura y llevado en las circunstancias dadas "una vida feliz" (Schneppen, 2002: 23).

Hasta el fin de su vida en el año 1858 Bonpland vivía ante todo en dos regiones: en San Borja en Brasil y en Argentina, al otro lado de la frontera, en la región de Corrientes y alrededor de Corrientes, donde reactivó su antigua hacienda Santa Ana, 180 kilómetros de San Borja. Desde estos dos lugares desarrolló una actividad admirable. Con gran energía y su eterno optimismo investigó la flora y fauna de las regiones citadas. Su actividad principal, sin embargo, fue la mejora de los métodos agrícolas. Tuvo grandes logros en el cultivo de tabaco, de ovejas merinas, la yerba mate, algodón y naranjos, vacuno y alfalfa (Bell, 2010: 99). De vez en cuando hizo planes de volver a Europa con sus colecciones aunque éstos no llegaron a realizarse.

Para compartir y mejorar sus conocimientos $\mathrm{y}$ para tener intercambios con científicos y políticos viajó hasta el fin de su vida en el año 1858 por Argentina, Uruguay y Brasil, y, después de la muerte de Francia en 1840, 
también viajó a Paraguay un año antes de su propia muerte, en 1857. En total hizo alrededor de 150 viajes y expediciones en estos cuatro países.

A principios de los años 1840 y dada por finalizada su relación con la francesa Adeline, Bonpland encontró una nueva compañera, la nativa Victoriana Cristaldo. Bonpland, ya con más de 70 años, tuvo con ella tres hijos: Carmen, que nació en 1843 en San Borja, así como Amado, que nació en 1844 en Santa Ana, y Anastasio que nació en 1847 en San Borja (Bonpland et López, 2001).

Después de su liberación en el año 1831 en Paraguay, Bonpland mantuvo una correspondencia intensa no solo con científicos y políticos nativos, sino también con colegas de Europa. Reanudó también la relación epistolar con Humboldt. Cuando Humboldt oyó en julio de 1831 que Bonpland había sido puesto en libertad, el primero le envió nuevamente, tal como en 1821, una cantidad modesta de dinero. Ante todo empleó todas sus fuerzas para conseguir que el gobierno francés le volviese a pagar a Bonpland la pensión de 3.000 francos como se estipuló en un principio.

En octubre de 1832 Bonpland envió a través del consulado francés de Buenos Aires 25 cajas con muestras zoológicas, botánicas y mineralógicas al "Muséum National d'Histoire Naturelle" de París. Procedían ante todo de Argentina, Brasil y Paraguay, pero también se encontraban entre ellas muchas muestras herborizadas y mineralógicas de la colección que había hecho con Humboldt durante la gran expedición en común. Lamentablemente especialmente estas últimas muestras habían sufrido mucho durante el confinamiento de Bonpland en Paraguay. Cuando llegó la colección en 1833 a París incluso faltaban los documentos adjuntos (Hamy, 1906: LXVIII y LXIX). Bonpland mandó a posteriori, el 5 de enero de 1837, una descripción detallada del contenido $^{23}$ (Hamy, 1906: 103-114). Referente al envío escribió el 7 de mayo de 1832 desde Buenos Aires a Humboldt:

"He encontrado siempre obstáculos en todos mis proyectos iniciados desde mi salida

\footnotetext{
${ }^{23}$ Bonpland al Director del Muséum National d’Histoire Naturelle, Buenos Aires, 5 de enero de 1837.
}

de Francia. Hay una mala estrella que me persigue desde hace quince años; quiero confiar en que mi destino se presentará de manera más feliz desde que he abandonado Paraguay. He vuelto con mis amigos y estoy nuevamente en contacto con la civilización y Europa, he retomado mi antiguo trabajo en la historia natural con mucho impetu para que pueda volver a mi patria lo antes posible"24 (Hamy, 1906: 82-83).

Y agrega el 1 de junio de 1832:

"Pienso que el gobierno [francés] estará contento con mi decisión, cuyo objetivo consiste en ser útil a las ciencias, de encontrar nuevos materiales y recuperar al menos una parte de lo que he perdido" 25 (Hamy, 1906: 84).

También en los años siguientes Bonpland envió muestras zoológicas, geológicas y botánicas a París. Así reanudó el anterior intercambio científico. Pero también lo hizo como agradecimiento por la pensión humilde que le estaba dando el gobierno francés. Bonpland completaba su manutención como médico y con la venta de productos agrícolas de sus plantaciones. Su sueño, sin embargo, de poder volver al menos por algún tiempo a Europa, no se realizó. El 28 de marzo de 1838 describió Bonpland a los 64 años en una carta a Humboldt desde Corrientes sobre las circunstancias de su vida que a menudo dependían de los disturbios políticos e inseguridades:

"La revolución invade a menudo la bonita provincia de San Pedro [= Misiones, región de su domicilio Santa Ana], ha atraido nuevas pérdidas. Mi consultorio médico me mantiene siempre y necesariamente entretenido, y con la ayuda de esta ocupación me encuentro honorable, reconocido y admirado por las mejores personas. Tengo acceso a las mejores casas. Mi carácter, mis pocas exigencias, mi comportamiento y, lo tengo que decir, las ganancias por mi actividad médica me otorgan felices días. Sin embargo, me perturba más que nunca el deseo de volver a Europa y

\footnotetext{
24 Bonpland a Humboldt, Buenos Aires, 7 de mayo de 1832.

${ }^{25}$ Bonpland a Humboldt, Buenos Aires, 1 de junio de 1832.
} 
comenzaría una nueva vida si tuviera el coraje de emprender nuevamente un viaje con mi herbario, mis manuscritos, mis anotaciones y de dejar nuevamente todo lo que poseo aqui que no podría llevar conmigo.

En medio del trabajo como médico tengo siempre tiempo de ocuparme de la historia natural. En los últimos dias he realizado un viaje al Chaco que me ha dado muchas nuevas $e$ interesantes impresiones. En este momento estoy llenando tres cajas para el Muséum [National d'Histoire Naturelle]. Al final de año les enviaré una nueva entrega, entre todo también unas plantas vivas, que solicitaron. Como ves, todavía tengo una vida activa, aunque mis fuerzas corporales me están abandonando un poco y no puedo ya obedecer a todos mis deseos.

Me gustaría emprender un gran viaje. Me gustaría visitar países que no se parecen en nada a lo que ya he visto. Muchas veces he pensado viajar a Argel, pero si pienso en la pobreza de las sierras del Atlas y en todo lo que me ha dicho el Sr. [René Louiche] Desfontaines [que habia investigado la botánica de Argel y de Túnez], me quedo tranquilo en los bordes de los ríos Uruguay y Paraná que frecuento alternativamente.

Si el tirano de Paraguay muriese antes de su noventa aniversario ${ }^{26}$, podría volver a Paraná [sic] y desde alli a Bolivia. Podría ver las cimas altas que no han sido medidas todavía. Y podría descubrir muchas cosas nuevas en este viaje.

Mi deseo es, estimado amigo, que te encuentres bien de salud igual que los tuyos que amas y aprecias. ¿Qué se sabe del Sr. Kunth? En medio de tantas solicitudes que he hecho no podía recibir ninguna noticia de él. Parto de la idea que está en Berlín y que ocupa el lugar de Willdenow y así siempre a tu lado. [...]

Te abrazo como siempre del fondo de mi corazón.

Tu devoto amigo,

Aimé Bonpland"27 (Hamy, 1906: 126-128).

${ }^{26}$ Francia nació en 1756 , tenía entonces ochenta y dos años. Murió dos años después de esta carta, en 1840.

27 Bonpland a Humboldt, Corrientes 28 de marzo de 1838.
La correspondencia entre ambos investigadores se mantiene de manera similar hasta el final de la vida de Bonpland en el año 1858. En total se han conservado más de 25 cartas detalladas. En todas ellas se habla de manera verdaderamente amistosa con mucha profundidad y de todo corazón. En el centro se encuentra el interés científico para la agricultura y la medicina de Bonpland, pero también su situación a veces preocupante financiera que se agravó por los disturbios políticos de aquella zona. Humboldt le animó para que se emplee también en lo sucesivo para sus ideales políticos en común. En febrero de 1843 le escribió desde París:

";Mantuve el coraje de seguir mis ideales como buen defensor de la libertad! La vida en las cortes no me perturbará. También los abusos que hicieron con convicciones democráticas no han podido desviarme de mis principios antiguos. Lamento profundamente la situación politica en América: Para un pueblo es más fácil ganar la independencia que la libertad. También en Europa los progresos de la libertad andan muy a rastras" (Hossard, 2004: 110) ${ }^{28}$.

También Humboldt anhelaba el regreso de su amigo, al menos por un tiempo, a Europa. Aunque también mostró comprensión para su vida en Latinoamérica:

"Comprendo la atracción del clima subtropical, la independencia de la vida, más cercana a las alegrías de la naturaleza, comprendo la magnitud de una larga y bonita costumbre. Tú amas a tu patria, pero temes la vida, que encontrarías, la dificultad de un nuevo comienzo, la frialdad de nuevos contactos que deberías crear. No puedo culparte a pesar del deseo imperioso de volverte a abrazar antes de la muerte que no debe estar muy lejos" 29 (Hossard, 2004: 109).

También Bonpland habló a menudo del deseo de un reencuentro. Escribió en enero de 1854 a Humboldt que sería su gran esperanza de poder acompañar él mismo una de sus colecciones a París, de introducirse en la nueva

\footnotetext{
${ }^{28}$ Humboldt a Aimé Bonpland, París, antes del 19 de febrero 1843.

${ }^{29}$ Humboldt a Aimé Bonpland, París, antes del 19 de febrero 1843.
} 
literatura y el estado reciente de la ciencia, de comprar libros y de volver entonces "para esperar tranquilamente al final en las orillas de su querido río Uruguay, rodeado por su misteriosa y fabulosa naturaleza"30 (Hamy, 1906: 183).

El material que envió en muchas partidas durante los años desde su liberación en 1832 hasta su muerte en 1858 a París, era muy abundante. La botánica Alicia Lourteig del "Muséum d'Histoire Naturelle" ha publicado en 1977 el resultado de su investigación de las colecciones de Bonpland. Los manuscritos de Bonpland abarcan varios miles de páginas. En ellos se encuentra también el citado "Journal Botanique" del viaje Bonpland-Humboldt. Se conservan en el museo aparte de las miles de muestras botánicas, zoológicas y geológicas del viaje en común con Humboldt otras miles de piezas coleccionadas por Bonpland. Sus posteriores diarios citan 2.884 números de plantas y una lista de minerales de un viaje a Uruguay en el año 1849 con 357 piezas en su totalidad. Sin duda, éstos solamente significan una pequeña parte de las muestras coleccionadas y enviadas a Europa. "Es indudable", escribe Alicia Lourteig, "que buena parte de sus colecciones se ha perdido" (Lourteig, 1977: 275). Las evaluaciones del material enviado al Museo han sido muy diferentes. Así, se encuentra por ejemplo en las 755 páginas de la descripción de la última colección de Bonpland, la del 1 de abril de 1859, es decir la que fue enviada después de su muerte desde Montevideo a París, la observación que se encontraba "en un estado lamentable" y no cumpliría " $n i$ de lejos las expectativas con que los científicos se acercarian a una colección del gran botánico Bonpland” (Lourteig, 1977: 301). Humboldt, por el contrario, escribió en 1835: "Has enviado unas estupendas colecciones" 11 (Hossard, 2004: 95).

Seguramente hubo investigaciones valiosas entre los trabajos de Bonpland. Así existe por ejemplo en Quito, Ecuador, un manuscrito

\footnotetext{
30 Bonpland a Humboldt, Montevideo, 29 de enero de 1854.

31 Humboldt a Bonpland, Paris, 14 de septiembre de 1835.
}

con el título "Floresta Americana - Atlas", que hizo Bonpland en 1850 en Montevideo $^{32}$ (Holl, 2001: 77). Contiene 135 dibujos de plantas, sobre todo medicinales y otras plantas útiles. A todas se les designa con su nombre en español y en lengua guaraní. Por lo menos el índice y las descripciones proceden de la pluma de Bonpland. Se supone que los dibujos fueron elaborados por un nativo de la tribu de los guaraníes. Esta obra es un testimonio válido de la estrecha cooperación de Bonpland con los guaraníes. En una de sus cartas a Humboldt, Bonpland elogiaba "el gran papel que los guaranies han tenido en el continente, aún después de la conquista"33 (Hamy, 1906: 89).

Sin embargo, es un hecho que no han surgido casi publicaciones del material tardío de Bonpland ${ }^{34}$ (Bell, 2010: 296). El problema añadido fue que Bonpland vivía demasiado lejos para seguir el progreso científico en Europa. Mucho material enviado que cruzó el Atlántico había sido descrito y publicado ya por parte de colegas en Europa (Bell, 2010: 144-145). El intercambio científico y las posibilidades de investigación habían sido impedidos por la comunicación intercontinental lenta y difícil. Se perdieron cartas y envíos de muestras biológicas y geológicas. Y también hubo problemas de comunicación en el lugar donde vivía Bonpland. Sólo el acceso a papel para escribir era difícil, las bibliotecas en Buenos Aires y Montevideo quedaban muy lejos. La comunicación con Humboldt, sin embargo, funcionaba de manera relativamente buena. A menudo Bonpland pidió a su antiguo compañero de viaje el envío de libros, por ejemplo algunos tomos de la obra botánica que habían realizado en común ${ }^{35}$ (Hamy, 1906: 85-86), y Humboldt le envió también sus nuevas publicaciones como p. ej. la nueva

\footnotetext{
32 El original se encuentra en la Biblioteca Nacional de Ecuador, Quito.

${ }^{33}$ Bonpland a Humboldt, Buenos Aires, 12 de julio de 1832.

34 La bibliografía de Stephen Bell solo contiene un título: Bemerkungen A. Bonpland's über die Verbreitungssphäre des Paraguay-Thee's. En: Zeitschrift für allgemeine Erdkunde 5 (1858), p. 76-83.

35 Bonpland a Humboldt, Buenos Aires, 1de junio de 1852.
} 
edición de los "Ansichten der Natur" (Cuadros de la naturaleza) y los tomos de su "Kosmos" (Cosmos) (Hamy, 1906: 170) ${ }^{36}$.

En el año 1853 el botánico de Nueva York John Teney, envió a Humboldt una foto portretada de Bonpland a Berlín ${ }^{37}$ (Hamy, 1906: 235), y a continuación Humboldt también envió a su compañero de viaje un retrato ${ }^{38}$ (Hamy, 1906: 185). Bonpland le agradeció emotivamente, y también le agradeció a Humboldt por la Orden del Águila Rojo ("Roter-Adler-Orden") igual que el Doctor Honoris Causa de la Universidad de Greifswald y la distinción con la Cruz de la Legión de Honor. Estaba consciente de que dichas distinciones las debía a la iniciativa de su compañero de viaje. Una de las mayores distinciones para él, sin embargo, fue que desde 1853 la revista botánica de la Academia Imperial Leopoldina-Carolina de los naturalistas llevaba según él el nombre de Bonplandia y que fue nombrado miembro de dicha academia (Schneppen, 2002: 27).

En diciembre de 1853 Bonpland soñaba de cruzar el océano con uno de los nuevos barcos a vapor de los cuales uno incluso llevaba el nombre Humboldt ${ }^{39}$ (Hamy, 1906: 172), y también en octubre de 1854, con 81 años, escribió a su amigo, cuánto le gustaría visitar nuevamente París y también Berlín. Decía que su estado de salud era bueno aunque se encontraba cansado después de una cabalgata de cinco o seis horas. Y reconoció cuánto le faltaba Humboldt: "Me parece que una conversación de pocas horas nos aportaría diez años de vida"40 (Hamy, 1906: 189). Aunque un año más tarde, en septiembre de 1855 , se entusiasmaba con las ventajas de la vida en el campo que prefería de lejos a la de las ciudades en aquellas zonas:

"En Santa Ana y Sao Borja respiro el aire puro. La sombra de los naranjos le convierte en

\footnotetext{
${ }^{36}$ Bonpland a Humboldt, Montevideo, 25 de diciembre de 1853.

${ }^{37}$ Humboldt a Bonpland, Sans-Souci, 1 de septiembre de 1853.

38 Bonpland a Humboldt, Montevideo, 3 de febrero de 1854.

39 Bonpland a Humboldt, Montevideo, 25 de diciembre de 1853.

${ }^{40}$ Bonpland a Humboldt, Restauración, 2 de octubre de 1854.
}

aire fresco y aromático. Mi vida en San Borja me recuerda continuamente a nuestra estancia en Ibagué [Colombia], y la temperatura tan agradable y muchas plantas que allí crecen en lugares parecidos. San Borja me recuerda también a nuestra estancia en Hyères y nuestro viaje a la costa desde Cullera entre Barcelona y Valencia. Tú estabas encantado en aquella época de los naranjos y soñabas de una vida en la sombra de estos naranjos. Son árboles valiosos que llevan hojas durante todo el año: verde oscuro en agosto, con pétalos que emanan un aroma exquisito y perturbador" (Hamy, 1906: 199).

Escribía que en Santa Ana el eterno "Kosmos" (Cosmos) y sus "Ansichten der Natur" (Cuadros de la Naturaleza) eran su única ocupación. Y sigue escribiendo:

"Me gusta entretenerme con la lectura de tus obras y me parece que te oigo hablar lo que me proporciona agradables recuerdos. Cuántas veces, querido Humboldt, he lamentado nuestra separación. [...] El hombre necesita un amigo fiel. Necesita descargar los sentimientos secretos de su corazón"42 (Hamy, 1906: 199200).

La vida inquieta que llevaba Bonpland no cesó hasta el fin de su vida en el año 1858. Parece incluso que cada vez que se hacía mayor aumentaba su actividad. De esta manera trabajaba desde 1853 para el gobierno francés en el proyecto para su colonia en Argel. Componía muestras de plantas útiles que según su parecer se podían cultivar allíi3 (Hamy, 1906: 185). Éste fue un sueño desde los años 1830, desde su liberación del confinamiento en Paraguay ${ }^{44}$ (Hamy, 1906: 85; Bell, 2010: 187-188). Argelia irónicamente había sido el objetivo de viaje inicial de Bonpland y Alexander von Humboldt que sin embargo no pudieron pisar por la nacionalidad francesa de Aimé Bonpland. En el año de 1830 habían

\footnotetext{
${ }^{41}$ Bonpland a Humboldt, Montevideo, 2 de septiembre de 1855.

${ }^{42}$ Bonpland a Humboldt, Montevideo, 2 de septiembre de 1855.

${ }^{43}$ Bonpland a Humboldt, Montevideo, 3 de febrero de 1854.

${ }^{44}$ Bonpland a Humboldt, Buenos Aires, 1 de junio de 1832.
} 
entrado tropas francesas en aquel país y pocos años más tarde el citado país estuvo gobernado por Francia. Bonpland igualmente mantuvo contacto con inversores franceses que tenían la intención de establecerse en Argentina, p. ej. con la casa comercial francesa Desmarest \& Ducoing cuyos representantes se interesaban por el cultivo del tabaco (Bell, 2010: 180). También fue consultor de la embajada francesa en Argentina en cuanto al asentamiento de colonizadores franceses (Bell, 2010: 181-182).

Otro gran proyecto que fue apoyado por Bonpland era la creación de un museo de ciencias naturales en Corrientes. El gobernador Juan Gregorio Pujol le había pedido su colaboración en la concepción de dicha institución y también aportar una parte de sus colecciones. El 10 de octubre de 1854 Bonpland fue nombrado su primer director (Cerruti, 2012: 65). En 1857 viajó con 83 años en el barco a vapor de guerra francés "Bisson" por el Río Paraguay hasta Asunción para ser recibido allí por el nuevo presidente Carlos Antonio López (Hamy, 1906: 87).

El 7 de junio de 1857 Bonpland escribió desde Corrientes su última carta a Alexander von Humboldt. Es una carta llena de optimismo y fuerza de voluntad. Bonpland informa que últimamente en la provincia de Corrientes se había muerto un hombre de 107 años y anota: “QQué perspectiva para nosotros dos que tenemos ahora más de 80 años y después de: haber cruzado tantas zonas climáticas y con tantas penurias!'”. Y agrega:

"¡Cuánto me haría feliz, mi querido Humboldt, poder charlar con un amigo que acaba de verte! ¡Cuántas preguntas tendría que hacerte sobre tu posición, tu salud y tu trabajo!

Nosotros dos estamos bien de salud y no pensamos abandonar este mundo, a pesar de las pérdidas diarias y las injusticias que vivimos. El Sr. Jules Fischer [el que entrega la carta] me ha encontrado en la sala prevista para el museo de Corrientes, y le enseñé con mucho gusto mis colecciones y ante todo mi herbario. Estoy ocupado en aportar todos los duplicados que he coleccionado en el curso de los años. [...]

El actual gobernador de Corrientes, Sr. D. Juan Pujol, es un hombre culto, muy liberal, muy patriótico y desea la suerte para su país; tuvo, diría yo, la idea feliz de crear un gabinete de historia de ciencias naturales, un museo de productos de Corrientes y de la confederación argentina. Para realizar proyectos tan útiles, el Sr. Pujol me llevó desde mi estancia hasta Corrientes. Estaba muy ocupado en mi estancia con la superación de parte de mis pérdidas en cuanto a ganado y otros animales. Todo lo que me quedó era el campo y mis plantaciones con frutales y otros árboles. Mi deseo era apoyar al gobernador con sus ideas útiles y le ofreci los dobles de todas mis colecciones y cumpliré con mis promesas. En cuanto que este trabajo esté terminado tendré que viajar por la provincia y la República Argentina, aunque si fuese posible preferiría llevar yo mismo mis colecciones a París para depositarlas junto a mis manuscritos en el museo y para emprender los pasos necesarios para la publicación de mi herbario lo que conlleva mucho interés.

Mi edad avanzada no me permite trabajar de noche. Después de seis horas de trabajo intenso durante el día tengo que descansar y no puedo soportar el trabajo de noche. Mi viaje a París sería por lo tanto muy corto y volvería a mi Santa Ana donde tengo cinco "Lieues" al cuadrado [= 20 kilómetros cuadrados] de superficie y varios miles de frutales útiles $y$ algunos animales que se multiplicarán posiblemente.

En Santa Ana, mi estimado amigo, vivo una vida tranquila y moriré alli y mis tristes restos descansarán en la sombra de muchos árboles. Lo que atañe a mi terreno en San Borja, nadie ha querido pagarme por los frutales numerosos que he plantado y que me han dado naranjas de un dulzor exquisito. Un amigo, un compadre, se ha ocupado de ellos mientras que yo espero a algo mejor. Trabajo, como tú ves, para reunir lo poco que me queda todavía en Santa Ana, donde paso dias tranquilos y felices. [...]

Me iré a San Borja donde tengo el proyecto de fabricar una cantidad importante de agua de flor de naranja y estaré de vuelta a finales de septiembre. Para entonces espero que las vitrinas y otros trabajos estarán terminados en el museo de Corrientes y trabajaré sin descanso en la terminación del museo [...]. Querido Humboldt, me he perdido en los 
detalles, pido perdón. Son las diez y terminaré mi carta y la entregaré al Sr. Jules Fischer. Por favor, hazme el favor de escribirme una palabra de vez en cuando y piensa en tu fiel amigo"45 (Hamy, 1906: 212-216).

A esta carta llena de entusiasmo y perspectivas positivas se contrapone un informe totalmente opuesto. Su contenido entró en muchas biografías de Humboldt y Bonpland. Influye en la imagen de los últimos años de Bonpland hasta hoy día. Se trata del relato del médico alemán y autor de libros de viajes Robert Avé-Lallemant. Él visitó a Bonpland pocas semanas antes de su muerte el 10 de mayo de 1858 en Santa Ana. De este relato existen tres diferentes versiones. La primera se publicó en la revista Bonplandia el 15 de julio de 1858. Se trata de dos cartas de AvéLallemant a Alexander von Humboldt. Una de las cartas fue escrita al lado del río Uruguay en San Borja el 10 de abril de 1858; la otra es de Uruguayana situada al lado del río Uruguay del 19 de abril de 1858 (Humboldt, 1858: 269272). En la segunda escribe Avé-Lallemant: "Ya había oído tanto del querido viejo y su raro cinismo que no me extrañó para nada encontrarlo en una situación extremadamente pobre, aunque esto me causara mucha pena" (Humboldt, 1858: 270). Sigue una descripción de una muy deteriorada estancia de Bonpland en Santa Ana, que consiste en dos chozas, de las cuales una solo se mantiene por el medio de troncos que la apoyan para prevenir el derrumbe.

"Una tabla ancha que se apoyaba en dos barriles servía de mesa; un banco y dos sillas, al lado de un lecho en el suelo formaban el mobiliario. No podía evitar un suspiro. Por fin apareció el viejo vestido de manera muy austera con camisa y pantalones; los ochenta y cinco años habian formado profundas arrugas en la querida y amable cara, cuyos ojos miraban alrededor todavía muy vivos y claros como no podía ser mejor. Me recibió de manera cariñosa y amable y se disculpó por los pobres enseres de la casa que quedaron aún más expuestos al invitarme a comer carne asada en un plato de estaño y no poderme ofrecer ni cuchillo ni tenedor. Después de

$\overline{45}$ Bonpland a Humboldt, Corrientes, 7 de junio de 1857. haber comido con la ayuda de mi navaja y los dedos entramos en miles de conversaciones que le causaron un poco de cansancio y le dejaron finalmente agotado" (Humboldt, 1858: 270).

Sigue escribiendo Avé-Lallemant que Bonpland todavía tiene "un montón de proyectos". Opina que la propiedad de Santa Ana que le fue regalado por el gobierno de Corrientes tiene un valor de "10.000 taleros españoles" (Humboldt, 1858: 271). Por lo tanto, Bonpland podría vivir mejor si vendiese esta propiedad. Sin embargo, dice que no acepta consejos. Según Avé-Lallemant, Bonpland todavía tiene colecciones y manuscritos en Corrientes. "Todavía colecciona y anota. [...] Él mismo admite que no ha podido mantenerse al nivel de la ciencia, y que seguramente se encuentran entre sus colecciones aparte de muchas piezas excelentes algunas anticuadas e incompletas" (Humboldt, 1858: 271). Avé-Lallemant termina su informe con las siguientes palabras:

"¡Cuánto me hubiese gustado convencer a él volver al mundo civilizado! Pero lo sentía con él: su tiempo había terminado. Ya no representaba el presente; pertenecía a la primera mitad del siglo XIX, no a la segunda: un monumento melancólico para todos que cazan durante la vida detrás de algo grande, loable en las ciencias y que únicamente se olvidan que cualquier flor de la mente solo tiene su aroma y su decoro y colorido donde esté entrelazado con sentido y mano hábil en la corona de las costumbres europeas" ${ }^{46}$ (Humboldt, 1858: 271).

Alexander von Humboldt sintió la necesidad de hacer imprimir en la revista Bonplandia, directamente después de dicho informe la carta tan positiva y que daba una impresión tan diferente de Bonpland del 7 de junio de 1857 (ver más arriba) en extractos y anotaba además: "Esta carta tan alegre y casi hambrienta de vida contrasta de manera rara con la descripción de la visita del Dr. Lallemant" (Humboldt, 1858: 271).

En el año 1859 Robert Avé-Lallemant publicó un libro con el título "Reise durch SüdBrasilien im Jahre 1858" (Viaje por el Sur de

\footnotetext{
${ }^{46}$ Subrayado de Avé-Lallemant.
} 
Brasil en 1858). También allí se encuentra la descripción de su visita en la casa de Bonpland. Sin embargo contiene detalles adicionales. Así se encuentran en ella la hija de 15 años de Bonpland y sus "hijos de alrededor de diez y doce años". Además escribe Avé-Lallemant sobre Bonpland:

"En la ciudad de Restauración el gobierno correntino le ha asignado una casita, sin embargo, viene solo de vez en cuando. Toda la ciudad ama al viejo Don Amado, él, sin embargo, no quiere nada de la ciudad entera. En breves palabras, hay que dejar actuar al viejo hasta que Dios quiera" (Avé-Lallemant, 1859: 366).

Una tercera versión de la visita a Bonpland en Santa Ana publicó Avé-Lallemant en 1872. Es la que más divulgada está de lejos ya que se encuentra en la primera gran biografía sobre Alexander von Humboldt, editado en tres volúmenes por Karl Bruhns (Bruhns, 1872). La estancia de Bonpland es caracterizada por Avé-Lallemant entre otras cosas de la siguiente manera: "El lugar aislado que carecia de cualquier comodidad y cultura me impresionó de manera muy desoladora" (Bruhns, 1872: vol. 2: 84). Las dos "cabañas grises de campo" le parecieron "pobres y sucios" (Bruhns, 1872: vol. 2: 83). En cuanto a la conversación con Bonpland relata lo siguiente:

"Aparentemente Bonpland vio no sin envidia el sobrepeso inmenso de su amigo. Opinó que Humboldt había publicado algunas de las investigaciones que correspondian a Bonpland; le había visto gustosamente su segunda ida a América porque tenía especiales compromisos con Kunth; que habia seguido trabajando con este último sin esperar su vuelta a Europa; y le habia desaconsejado incluso a menudo volver a Europa. También se quejó que en Europa su segundo viaje americano no fue reconocido suficientemente igual que sus colecciones en cuanto a su valor que había enviado (Bruhns, 1872: vol. 2: 85).

Las múltiples contradicciones de las diferentes versiones textuales constituyen un índice importante de que las quejas de Bonpland sobre su supuesta injusticia que este dice que Humboldt le hubiese causado, no corresponden a la verdad. Si se conoce la historia de la relación entre ambos investigadores y el tono cordial e incluso cariñoso de sus cartas, queda claro que las citadas afirmaciones de Avé-Lallemant no pueden corresponder a la verdad. Solo la última frase sobre el menosprecio de las colecciones enviadas a Europa pudieran corresponder a una verdadera frase de Bonpland.

Si se investiga a los tres informes de AvéLallemant según su veracidad, queda bien claro que hay muchas incongruencias. Solo las diferencias que surgen de la comparación, delatan este hecho. De esta manera se menciona en el segundo informe de 1859 que a Bonpland le pertenecía una casa en la ciudad. Por ello no podía haberse encontrado en una "situación tan miserable", tal como lo describe AvéLallemant en su primera versión de 1857. Bonpland prefería, tal como lo escribe él mismo a su amigo Humboldt "una vida tranquila" en Santa $\mathrm{Ana}^{47}$ (Hamy, 1906: 214) a la vida en la ciudad. En el texto de Avé-Lallemant de 1872 también se encuentra la siguiente afirmación:

"Como recuerdo le pedí su firma con su propio puño y letra, y me escribió en el dorso de una carta vieja: "Aimé Bonpland". - "No me salió bien", dijo y escribió de nuevo; pero le salió peor. "Ya no puedo escribir", exclamó y me pareció que una lágrima se escapaba de su ojo. Quizás fue la última vez que escribiera su nombre" (Bruhns, 1872: vol. 2: 86).

En contra de esta afirmación Aimé Bonpland sí se encontraba en condiciones de poder escribir de manera clara y explícita. Por un lado lo demuestra Avé-Lallemant mismo que escribe en su primera descripción: "Todavía colecciona y anota" (Bruhns, 1872: vol. 2: 271). Por el otro lado existe de Bonpland mismo un informe bien legible y de su puño y letra a su vecino Karl Wilhelm Kasten sobre la visita de Avé-Lallemant (Bell, 2010: 216). Y por supuesto comía Bonpland normalmente con cuchillo y tenedor. Sin embargo, poco antes un hombre de su servicio le había robado los cubiertos (Bell, 2010: 216). Bonpland pidió a su visitante Avé-Lallemant, que dijera a su vecino Kasten que consiguiera nuevos cubiertos (Bruhns, 1872: 86). El biógrafo Stephen Bell además señala con razón el hecho que poco antes de la visita de Avé-Lallemant

${ }^{47}$ Bonpland a Humboldt, Corrientes, 7 de junio de 1857. 
una plaga de saltamontes había arrasado la estancia y que Avé-Lallemant tenía que haberlo sabido (Bell, 2010: 224).

Dado que Robert Avé-Lallemant fue uno de los autores oficiales de la biografía célebre de tres tomos de Humboldt de Karl Bruhns, los lectores creyeron ciegamente en los contenidos expuestos. Así se formó la leyenda del pobre cínico desagradecido y mal tratado compañero de viaje de Humboldt, que murió abandonado en el fin del mundo en su estancia sucia de Santa Ana. Fue trasmitido en docenas de biografías sobre Humboldt y Bonpland hasta la actualidad, así p. ej. por Ernest Théodore Hamy, Lotte Kellner, Douglas Botting, también por parte de biógrafos de Bonpland recientes Nicolas Hossard en 2001 y Heinz Schneppen en 2002 (Hamy, 1906: 8990; Kellner, 1963: 90-91; Botting, 1994: 222; Hossard, 2001: 144-146; Schneppen, 2002: 29-30). Ya Alexander von Humboldt expresó dudas en cuanto al informe de Avé-Lallemant. Stephen Bell ha profundizado esta duda más de 150 años más tarde. Fue el gran logro de Bell que comenzó a crear una nueva imagen de Bonpland. A través de la comparación de los informes diferentes y contradictorios de AvéLallemant entre sí y de sus textos con otros hechos históricos, ante todo la correspondencia entre Bonpland y Humboldt, queda totalmente claro qué injusticia ha cometido Robert AvéLallemant referente a Aimé Bonpland.

En cuanto a las razones de esta manera tendenciosa y difamatoria de escribir historia solo se pueden hacer suposiciones. ¿Fue un intento de aumentar el prestigio de Humboldt y de disminuir el de su acompañante? ¿Fue el contexto de la guerra alemana-francesa de 1870/71, que impulsó al autor de dibujar una imagen negativa del francés? De todas maneras es imprescindible de corregir esta imagen tan negativa de Bonpland.

\section{Conclusiones}

El viaje de Bonpland a Argentina en 1816 fue una emancipación de la sombra que proyectaba Humboldt a Bonpland. Bonpland tenía el pleno derecho de hacer su vida independiente en Latinoamérica. Humboldt nunca se ha enfadado por ello. La elaboración del herbario en París fue un asunto largo y meticuloso que no cualquiera estaba dispuesto a realizar, menos aún cuando este trabajo se extendía por décadas. En Latinoamérica, sin embargo, Bonpland se podía realizar según sus propias decisiones.

En su nueva patria sudamericana Bonpland disfrutaba de reputación y admiración aunque en esa época a penas siguió publicando trabajos. Las razones yacían por un lado en las posibilidades de publicación allí mismo que se presentaban de manera mucho peor que en Europa. Además Bonpland no tenía acceso en las ciudades donde vivía a bibliotecas con literatura botánica correspondiente. $\mathrm{Su}$ vida se desarrollaba como una oscilación entre la investigación botánica, la agricultura práctica y el trabajo como médico. Todo ello le proporcionó en su nueva patria un gran prestigio. Dicho reconocimiento le hubiese sido denegado después de un posible retorno a Europa. Esta fue la razón porque Bonpland, a pesar de hablar durante décadas en sus cartas de su regreso, nunca volvió. Hubiese sido un retorno que le hubiese devuelto a la sombra de Humboldt.

También en Sudamérica Bonpland conservó sus ideales políticos. Tal como Humboldt fue defensor de los ideales de la Revolución Francesa: libertad, igualdad y fraternidad y defensor de los derechos humanos. Al igual que Humboldt, Bonpland respetaba la cultura indígena y ha trabajado junto a los aborígenes, especialmente en la agricultura y en la investigación de plantas útiles para la medicina y otros fines. Hablaba siempre de los guaraníes con mucho respeto. "iEl hombre debe aspirar a lo bueno y sublime!"48 (Päßler et al., 2019) - este ideal de Humboldt también era válido para Bonpland. Durante toda su vida fue consciente de su responsabilidad social como científico.

Bonpland fue y se portó durante toda su vida como coleccionista y hombre de la práctica. Humboldt sin embargo siempre tenía en mente la totalidad y ha demostrado de manera

\footnotetext{
48 Alexander von Humboldt a Karl Ludwig Willdenow. Aranjuez, 20 de abril de 1799; La Coruña, 5 de junio de 1799. https://edition-humboldt.de/v5/H0001200
} 
excepcional esta visión global de la tierra con la publicación de su "Kosmos" (Cosmos). En Argentina, sin embargo, Bonpland ha desarrollado su propia visión del mundo. Ha encontrado allí una nueva patria, aunque se sentía a menudo vascilando entre varias opciones. Inquieto y sin obtener el sosiego intentó realizarse allí. Tal como Humboldt desarrolló una energía constructiva, de la cual muchos disfrutaban especialmente en la práctica agrícola.

$\mathrm{Su}$ colaboración en el desarrollo del viaje Bonpland-Humboldt fue fundamental. Humboldt significaba la gran suerte para Bonpland, pero también Bonpland significaba esta suerte para Humboldt. Bonpland igual que Humboldt llevó a cabo algo gigantesco durante el viaje. La investigación botánica se encontraba en el centro de la expedición. El sitio que ocupa en la valoración de la expedición es cosa del observador. Cada cual y cada época da un valor distinto al viaje $\mathrm{y}$ de las publicaciones que surgieron del mismo. Se debe fijar sin embargo un hecho: en cuanto al número de los tomos publicados, la botánica se destacaba de lejos. El material botánico coleccionado para tal fin en el trabajo de campo era casi exclusivamente de Bonpland.

El biógrafo de Humboldt, Hanno Beck, constató con acierto que "la triada de un viaje histórico" (Beck, 1985: 301) de una expedición exitosa consistía en la preparación, la realización y la publicación. La participación en el sonido del medio, la realización, fue decisivamente de Aimé Bonpland, sin embargo, no en la preparación $\mathrm{y}$ al final muy poco en la elaboración y la publicación del viaje. Sin embargo, la publicación sin la participación de Bonpland no hubiese podido llevarse a cabo. Muy decisivo por lo tanto fue para su posterior renombre que bajo la presión de Humboldt entregó en Le Havre antes de su salida para Argentina el "Journal botanique" a su colega botánico Kunth.

Humboldt, esto hay que dejarlo claro, nunca se ha demostrado enfadado sobre los caminos nuevos de Bonpland y ha seguido manteniendo el contacto con él. Ha eternizado a Bonpland como coautor de su obra de viaje, también con las siglas botánicas HBK Humboldt-Bonpland-Kunth.

Bonpland siguió formando a través de la abundante correspondencia, también en Argentina, una parte del equipo de Humboldt, un equipo que consistía en el fondo de todos los científicos del mundo que tenían interés en colaborar con él. En la correspondencia de ambos investigadores se demuestra su grandeza y su voluntad para seguir un intercambio científico. Se basaba en el mutuo respeto y una cariñosa amistad. Su última carta, que ya no llegó a las manos de Bonpland, Humboldt terminó con las siguientes palabras: "No hay nadie en esta tierra que te quiera más que yo con todo su corazón y sentimiento"49 (Schneppen, 2002: 40). Junto con este último escrito de Humboldt, el "Botanisches Museum de la Universidad de Greifswald" que en 1856 había otorgado el Doctor Honoris Causa a Bonpland, envió a éste una gran caja con 600 muestras de plantas a Argentina. Estas muestras estaban destinadas al Museo de Corrientes de Bonpland ${ }^{50}$ (Schneppen, 2002: 41-42). Esta fue una de las muchas señales de que el investigador no había sido olvidado en Europa.

La valoración de la personalidad de Bonpland y de su labor no está nada concluida. El biógrafo Stephen Bell ha descubierto en los últimos años muchos datos nuevos y ha diseñado una imagen mucho más clara e indica el camino para seguir investigando. También Cédric Cerruti ha aportado ideas nuevas. Sin embargo, es sumamente importante seguir trabajando en ello y colocar el trabajo de Bonpland en un contexto aún más amplio, actual y mirando hacia el futuro. Bonpland se merece desde cualquier punto de vista una atención más amplia e internacional. $\mathrm{Y}$ también es necesario corregir la imagen negativa de Bonpland expuesta por Robert Avé-Lallemant al mundo. Bonpland ha hecho grandes cosas, también sin Humboldt. Se le merece ser redescubierto.

\footnotetext{
${ }^{49}$ Humboldt a Aimé Bonpland, Berlin, 10 de junio de 1858.

50 Julius Münter a Dietrich Georg von Kieser, Greifswald, 11 de febrero de 1860.
} 


\section{Agradecimientos}

Especialmente a Irene Prüfer por la traducción del artículo del alemán, también a Susanna Stein por la ayuda para entender las cartas en francés de Bonpland y a Maryam Bonpland por facilitar la genealogía de su familia.

\section{Bibliografía}

AVÉ-LALLEMANT, R. (1859). Reise durch SüdBrasilien im Jahre 1858. Brockhaus, Leipzig.

BECK, H. (1985). Alexander von Humboldts Amerikanische Reise. Edition Erdmann, Stuttgart.

BELL, S. (2010). A Life in Shadow: Aimé Bonpland in Southern South America, 1817-1858. Stanford University Press, California. https://doi.org/10.11126/stanford/9780804752602. 001.0001

BONPLAND, C. \& LÓPEZ, J. A. (2001). Genealogía de la Familia Bonpland. Buenos Aires - Mendoza 2001. Archivo de Powerpoint, todavía no publicado.

BOTTING, D. (1994). Humboldt and the Cosmos. Prestel, Munich, New York .

BRUHNS, K. (ed.) (1872). Alexander von Humboldt. Eine wissenschaftliche Biographie, 3 vols. Brockhaus, Leipzig.

CERRUTI, C. (2012). Un sabio acorrentinado - Amado Bonpland, un hombre al servicio de la ciencia y de Corrientes. Moglia Ediciones, Corrientes.

FAAK, M. (ed.) (2000). Alexander von Humboldt - Reise durch Venezuela. Auswahl aus den amerikanischen Reisetagebüchern. Akademie-Verlag, Berlin.

GLAUBRECHT, M. (2019). "Un peu de géographie des animaux". Die Anfänge der Biogeographie als "Humboldtian science". En: edition humboldt digital, ed. por Ottmar Ette. Berlin-Brandenburgische Akademie der Wissenschaften, Berlin. Version 5 vom 11.09.2019. URL: https://edition-humboldt.de/ v5/H0017686

HAMY, E. T. (1906). Aimé Bonpland. Sa vie, son oevre, sa correspondence. E. Guilmoto, París.

HOLL, F. (ed.) (2001). El Regreso de Humboldt. Exposición en el Museo de la Ciudad de Quito, Junio-Agosto del 2001. Asociación Humboldt Centro Goethe, Quito.

HOSSARD, N. (2001). Aimé Bonpland (1773-1853), médecin, naturaliste, explorateur en Amérique du Sud. L'Harmattan, París.
HOSSARD, N. (ed.) (2004). Alexander von Humboldt \& Aimé Bonpland. Correspondance 1805-1858, Paris [y otras]. L'Harmattan, París.

HUMBOLDT, A. VON (1845). Kosmos. Entwurf einer physischen Weltbeschreibung, Bd. 1. Cotta, Stuttgart und Tübingen. https://doi.org/10.5962/ bhl.title. 4717

HUMBOLDT, A. VON (1858). Neueste Nachrichten über Aimé Bonpland an Alexander von Humboldt. (Auszüge aus Briefen des Letztern an den Herausgeber.). En Bonplandia, 6. Jg., Nr. 13, 15. Juli 1858, S. 269-272.

HUMBOLDT, A. VON (1880). Briefe Alexander's von Humboldt an seinen Bruder Wilhelm. Hg. von der Familie von Humboldt in Ottmachau. Cotta, Stuttgart.

HUMBOLDT, A. VON (1991). Reise in die ÄquinoktialGegenden des Neuen Kontinents. Ed. de Ottmar Ette. Frankfurt am Main. Insel, Leipzig.

JAHN, I. \& LANGE, F. G. (eds.) (1973). Die Jugendbriefe Alexander von Humboldts 17871799. Akademie-Verlag, Berlin.

KELLNER, L. (1963). Alexander von Humboldt. Oxford University Press, London.

KÜGELGEN, H. VON \& SEEBERGER, M. (1999). Humboldt und Bonpland in Enders Urwaldatelier. En: HOLL, F. (ed.) Alexander von Humboldt - Netzwerke des Wissens. Begleitbuch zur Ausstellung im Haus der Kulturen der Welt Berlin und in der Kunst- und Ausstellungshalle der Bundesrepublik Deutschland Bonn. Hatje Cantz, Ostfildern.

LACK, H. W. (2003). Alexander von Humboldt und die botanischen Sammlungen in Berlin. En: Alexander von Humboldt in Berlin. Sein Einfluß auf die Entwicklung der Wissenschaften. Beiträge zu einem Symposium, ed. por Jürgen Hamel, Eberhard Knobloch, Herbert Pieper, = Algorismus. Studien zur Geschichte der Mathematik und der Naturwissenschaften 41. Erwin Rauner, Augsburg.

LACK, H. W. (2009). Alexander von Humboldt und die botanische Erforschung Amerikas. Prestel, München.

LOURTEIG, A. (1977). Aimé Bonpland. Bonplandia 3: 269-317. https://doi.org/10.30972/bon.3162590

MINGUET, C. (ed.) (1989). Alejandro de Humboldt - Cartas Americanas. Bibliotéca Ayacucho. $2^{\mathrm{a}}$ edición, Caracas.

MOHEIT, U. (ed.) (1993). Alexander von Humboldt - Briefe aus Amerika. Akademie-Verlag, Berlin.

PÄßLER, U., GERLACH, K. \& SCHWARZ, I. (2019). En edition humboldt digital, ed. de Ottmar 
Ette. Berlin-Brandenburgische Akademie der Wissenschaften, Berlin. Versión 5 del 11/09/2019, URL: https://edition-humboldt.de/
SCHNEPPEN, H. (2002). Aimé Bonpland - Humboldts vergessener Gefährte? Berlin: Alexander-vonHumboldt-Forschungsstelle. 
